\title{
ELECTRONIC COUNTING AND SIZING OF MAMMALIAN SPERMATOZOA AND CYTOPLASMIC DROPLETS
}

\author{
J. M. O'DONNELL \\ A.R.C. Institute of Animal Physiology, Babraham, Cambridge
}

(Received 12th June 1968)

\begin{abstract}
Summary. Comprehensive testing has confirmed the ability of an electronic cell counter to determine the volumes of ejaculated and immature spermatozoa of bull, ram and boar. It was found that the modal volume of free cytoplasmic droplets in semen of these species was about one-third that of ejaculated, droplet-free spermatozoa. Electronic estimates of the volumes of spermatozoa with and without droplets, free droplets and separated heads and tail midpieces were consistent with one another; volumes found for heads and tail midpieces of bull spermatozoa were in agreement with the most reliable estimates made microscopically.

There was found to be a skewness towards larger volumes than the mode for ejaculated spermatozoa; this feature was also observed in the heads but not in the tail midpieces of bull spermatozoa. The electronically-determined mean cell volume varied widely among ejaculates. Some positive correlation was found between mean cell volume and the percentage of cells impermeable to eosin in twenty-nine ejaculates from several different bulls.
\end{abstract}

\section{INTRODUCTION}

In recent years, microscopical cell counting and size measurement have been augmented by electronic methods. The ability of an electronic counting device, such as the Coulter counter, to measure sperm numbers in semen has been established for ejaculates of man (Segal \& Laurence, 1962; Gordon, Moore, Thorslund \& Paulsen, 1965), bull (Glover \& Phipps, 1962; Glover, 1964; Iversen, 1964a), guinea-pig (Laurence \& Carpuk, 1963) and rabbit (Fowler \& Hellman, 1965; Kihlström \& Fjellström, 1967). All of these workers reported a high correlation between haemocytometer and electronic counts when precautions were taken to ensure that only spermatozoa of semen were being counted electronically.

The apparent volumes of individual spermatozoa, as indicated by electronic measurement, are more difficult to verify by independent means. Glover noted the unexpected width of the volume distribution measured in this way as compared to direct observations of cell dimensions, and also the skewness of 
the distribution towards volumes higher than the mode. Similar observations have been made for human spermatozoa (Segal \& Laurence, 1962; Gordon et al., 1965).

In the present work, the method has been increased in resolution by the use of finer intervals in volume distribution than those hitherto employed, and its application extended to semen of ram and boar in addition to bull. Since bull and ram spermatozoa from the epididymis are demonstrably larger than those in the ejaculates due to the possession of the cytoplasmic droplet, these were also counted. Boar semen provided a mixture of both types of cell. The theory upon which electronic volume measurement is based cannot easily be applied to such an asymmetrically shaped cell as the mammalian spermatozoon (Gregg \& Steidley, 1965); therefore heads and tail midpieces of ejaculated bull spermatozoa were separately measured for comparison with intact cells.

\section{MATERIALS AND METHODS}

Semen from normal bulls and from a boar was taken by means of an artificial vagina and ram semen was obtained by electro-ejaculation. A Guernsey bull having a defect of spermatogenesis provided 'naturally-decapitate' bull spermatozoa. Testicular fluid was collected from rams by the method of Waites \& Setchell (1964). Bull spermatozoa from the first curvature of the caput epididymidis were obtained by expressing the contents from that part of the genitalia, removed and excised immediately after slaughter.

Semen samples were taken to the laboratory in thermally-insulated glass tubes. The time elapsing between collection and dilution of semen for counting did not in any instance exceed $60 \mathrm{~min}$ in the case of fresh samples. The duration of collection of testicular fluid from the rams was restricted to the minimum time necessary to accumulate sufficient cells to count, usually a period between 30 and $60 \mathrm{~min}$. Epididymal bull spermatozoa were prepared and counted within 90 min of slaughter.

Semen was mixed gently and diluted with sterile, dust-free $0.154 \mathrm{M}-\mathrm{NaCl}$ in distilled water. For counting, bull semen was diluted 1:2000 or 1:5000, ram semen was diluted 1:10,000, and other materials as required to yield an equivalent final concentration of cells. All counting was done at 18 to $20^{\circ} \mathrm{C}$.

Electronic counting was performed using a model B Coulter counter. A $50-\mu$ diameter aperture tube was calibrated with pores of mean diameter $3.616 \mu$. With instrument settings of amplification $=2$ and aperture current $=\frac{1}{2}$, the calibration gave 1 instrument threshold unit $=0.996 \mu^{3}$. To obtain volume distributions, diluted cell suspensions were counted at intervals of 0 to 2,2 to 4 , 4 to 6 , etc., instrument units until no further significant count was recorded. Dilutions were such as to reduce the probability of coincidence counting errors to a minimum. In the presentation of results, actual counts (mean of two) are plotted against the mean volume corresponding to each instrument setting, e.g. the mean volume of all particles registered between 12 and 14 units was taken as $13 \mu^{3}$.

Heads and tail-midpieces of bull spermatozoa were separated by densitygradient centrifugation (Nelson, 1966). 
Live and dead bull spermatozoa were distinguished and counted by the nigrosin-eosin staining technique (Campbell, Hancock \& Rothschild, 1953).

\section{Bull semen}

\section{RESULTS}

A typical distribution of particle volumes in a fresh sample of bull semen is shown in Text-fig. 1(a). The very high counts at the lower end of the volume scale are background due to electronic noise and impurities in the diluent, and

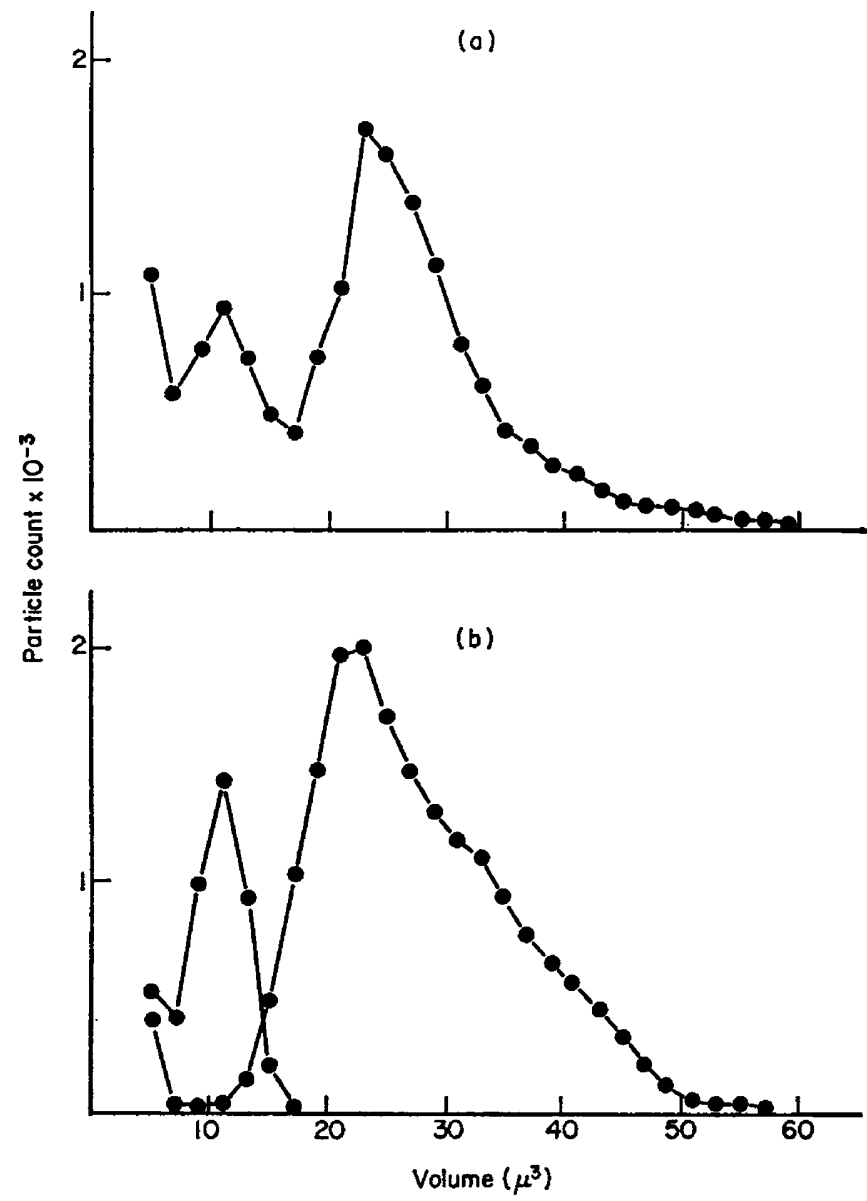

TEXT-FIG. 1. (a) Volume distribution patterns of a sample of fresh normal bull semen. (b) Volume distribution patterns of bull spermatozoa and cytoplasmic droplets separated by centrifugation.

are found in the diluent as such. Two modes for bull semen are typically found, at $11 \mu^{3}$ and in the range 19 to $25 \mu^{3}$, there being considerable variation between samples in the precise position of the second mode. The mode at the greater volume corresponds to that described by Glover (1964) for bull semen, while the smaller volume mode has not been previously reported for any species, and 
would not be detected with the use of counting intervals much coarser than $2 \mu^{3}$.

A comparison of electronic and haemocytometer counts showed that the spermatozoa in a semen sample could be accounted for by the larger particles alone, since electronic counts of larger particles were within $5 \%$ of manual counts made in two different laboratories on the same samples (H. M. Dott, personal communication). Further effort was therefore directed to identifying the origin of the particles of smaller modal volume. When a fresh semen sample was centrifuged at $300 \mathrm{~g}$ for $10 \mathrm{~min}$, virtually all of the spermatozoa were found in the pellet. Diluted pellet and supernatant then gave the distribution patterns shown in Text-fig. 1(b). Storage of semen at temperatures 20 or $4^{\circ} \mathrm{C}$ resulted in a progressive diminution in magnitude of the first peak, this decrease occurring more rapidly at the higher temperature. The smaller particles were also abolished by heating a fresh semen sample to $50^{\circ} \mathrm{G}$ for $30 \mathrm{~min}$, or by the addition of tris-HCl $(\mathrm{pH} 7.2)$ to a final concentration of $0.012 \mathrm{~m}$ in the diluent used for counting. Phosphate or citrate buffer added to the medium at the same $\mathrm{pH}$ and concentration did not have this effect.

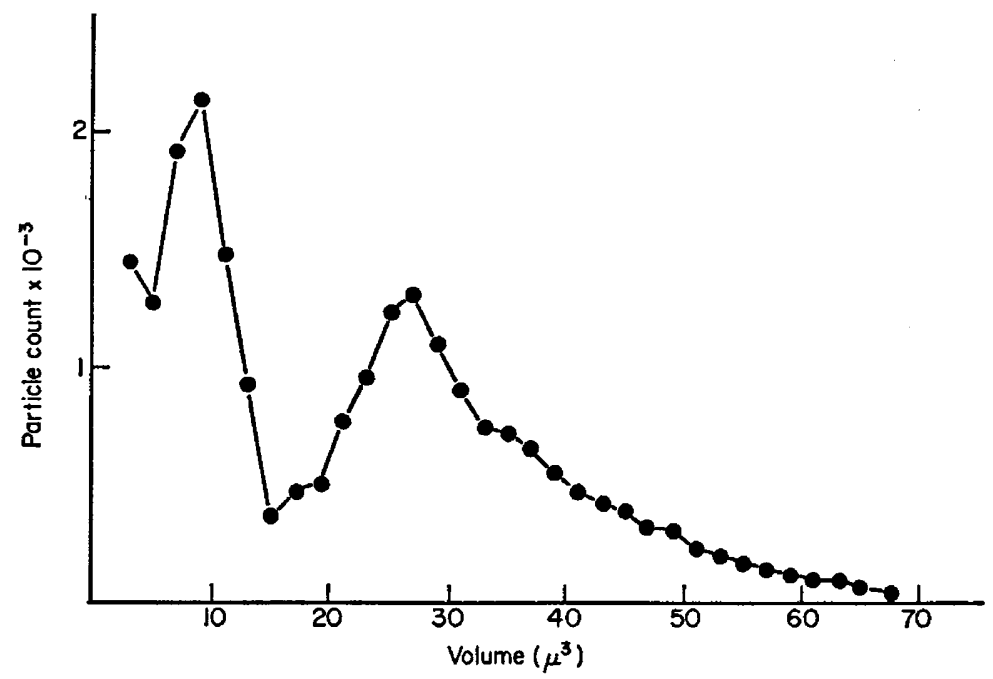

Text-FIg. 2. Distribution of particle volumes in fresh ram semen.

Light microscopic examination of the supernatant obtained when fresh semen was centrifuged as described above showed that the smaller particles in semen were free cytoplasmic droplets. Plate 1 shows unfixed, negativelystained electron micrographs of the droplets, the dimensions of which correspond with the modal volume of the droplets as indicated by the electronic counter. The dimensions and lability of the free droplets are in agreement with those reported by Dott \& Dingle (1968), and with the dimensions found by Bloom \& Nicander (1961).

\section{Ram semen}

Freshly-examined samples of ram semen also characteristically showed a varying proportion of smaller particles in addition to spermatozoa (Text-fig. 2). 
The dimensions and lability of these smaller particles suggested that these were cytoplasmic droplets, and visual examination of the supernatant yielded by gentle centrifugation confirmed this. As in bull semen the volumes of ejaculated ram spermatozoa were not symmetrically distributed but showed a marked skewness towards the right of the mode.

\section{Immature ram and bull spermatozoa}

Fluids collected from the efferent duct of the testis in a ram and expressed from the caput epididymidis in the bull were counted in the same manner as semen and the results are shown in Text-figs. $3(\mathrm{a})$ and 3(b). No peaks could be distinguished at the volumes corresponding to the free droplets in semen, and the single populations found in each case were spermatozoa all with droplets attached. The modal volumes for these (Table 1) were greater than those found for the corresponding ejaculated spermatozoa; the increment in modal volume was in each case somewhat greater than the volume registered by the free droplets of semen (Table I).

\section{TABLE 1}

SUMMARY OF DATA FROM ELEGTRONIC VOLUME ESTIMATIONS (VOLUMES IN $\mu^{3}$ )

\begin{tabular}{|c|c|c|c|c|}
\hline & & $\begin{array}{l}\text { Modal } \\
\text { volume }\end{array}$ & & $\begin{array}{l}\text { Modal } \\
\text { volume }\end{array}$ \\
\hline Bull & $\begin{array}{l}\text { ejaculated spermatozoa } \\
\text { cytoplasmic droplets } \\
\text { epididymal spermatozoa } \\
\text { ejaculated heads } \\
\text { ejaculated tail midpieces }\end{array}$ & $\begin{array}{l}19 \text { to } 25^{*} \\
9 \text { to } 11^{*} \\
37 \text { to } 41^{*} \\
13 \\
7\end{array}$ & $\begin{array}{c}\text { Ram ejaculated spermatozoa } \\
\text { cytoplasmic droplets } \\
\text { testicular spermatozoa } \\
\text { Boar ejaculated spermatozoa } \\
\text { cytoplasmic droplets }\end{array}$ & $\begin{array}{l}25 \text { to } 29^{*} \\
9 \text { to } 11^{*} \\
37 \text { to } 45^{*} \\
21,29 \\
9\end{array}$ \\
\hline
\end{tabular}

* Range.

The volume distribution patterns of immature bull and ram spermatozoa were extremely labile in comparison with those of ejaculated spermatozoa. Whereas ejaculated spermatozoa retained a relatively constant pattern, even when semen was treated in such a way as to abolish droplets completely, the volume distributions of immature spermatozoa diluted for counting altered significantly in periods as short as $30 \mathrm{~min}$ from the time of the initial counting. The peaks found for fresh dilutions gradually subsided to plateaux covering the complete range of instrument settings. The true modal volumes for such spermatozoa may be significantly different from those illustrated, since considerable periods of time were required for their preparation for counting. The lability of the pattern with time may have been due to differences in osmotic behaviour as compared to mature spermatozoa, or to changes in the membrane properties and hence in electrical resistance of these cells caused by processing for counting.

\section{Boar semen}

Semen of the boar differed from that of bull and ram in that it contained a high proportion of spermatozoa with cytoplasmic droplets still attached. A fresh sample counted in the same way as ram and bull semen gave the volume 


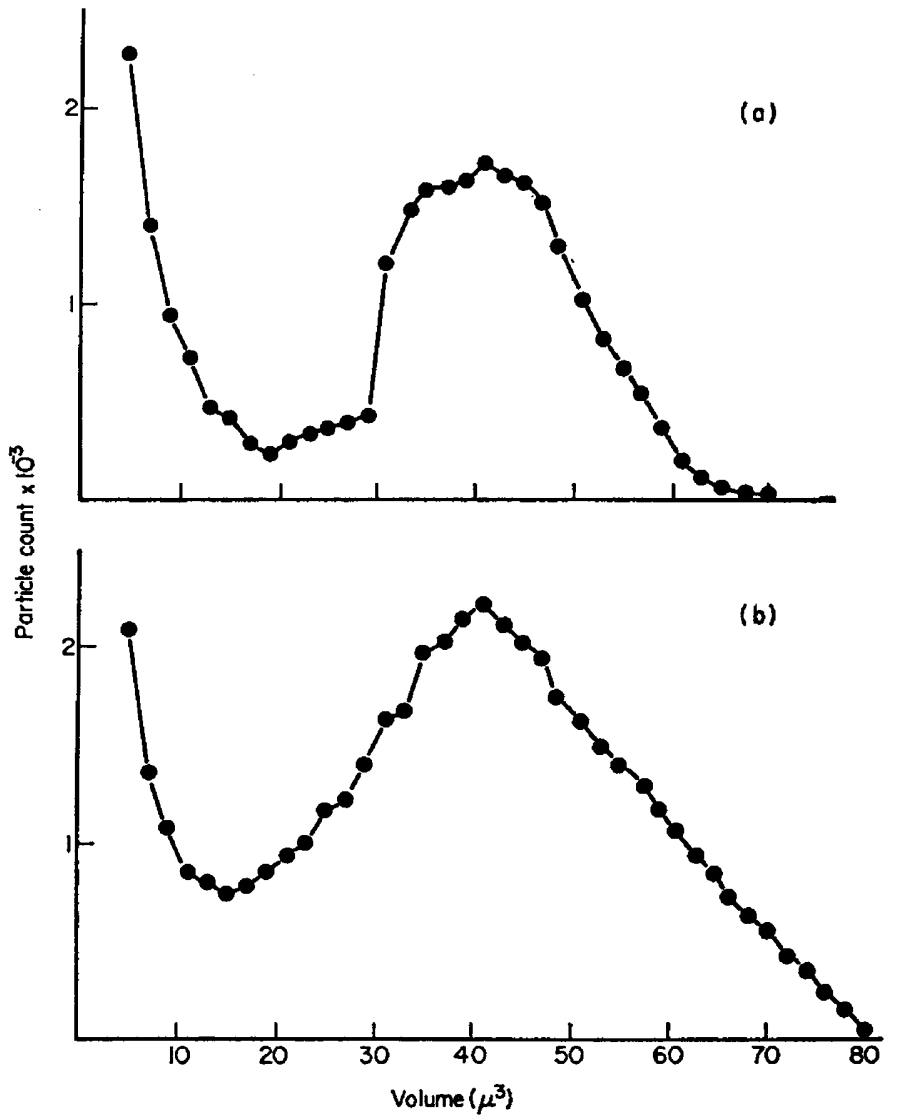

TEXT-FIG. 3. Volume distribution patterns of spermatozoa (a) from the efferent duct of a ram testis, counted within 60 min from start of fluid collection, and (b) from the region of first curvature in the caput epididymidis of a bull, counted $90 \mathrm{~min}$ after slaughter.

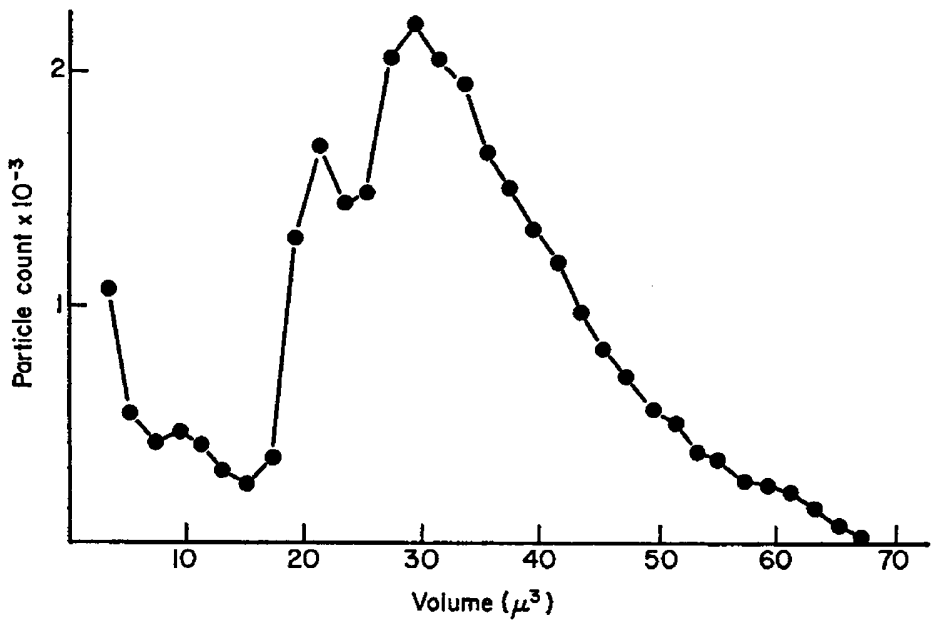

Text-Fig. 4. Volume distribution pattern in fresh boar semen. The two modes, at $29 \mu^{3}$ and at $21 \mu^{3}$, are due to spermatozoa with and without attached droplets, respectively. 
PI. ITI: 1

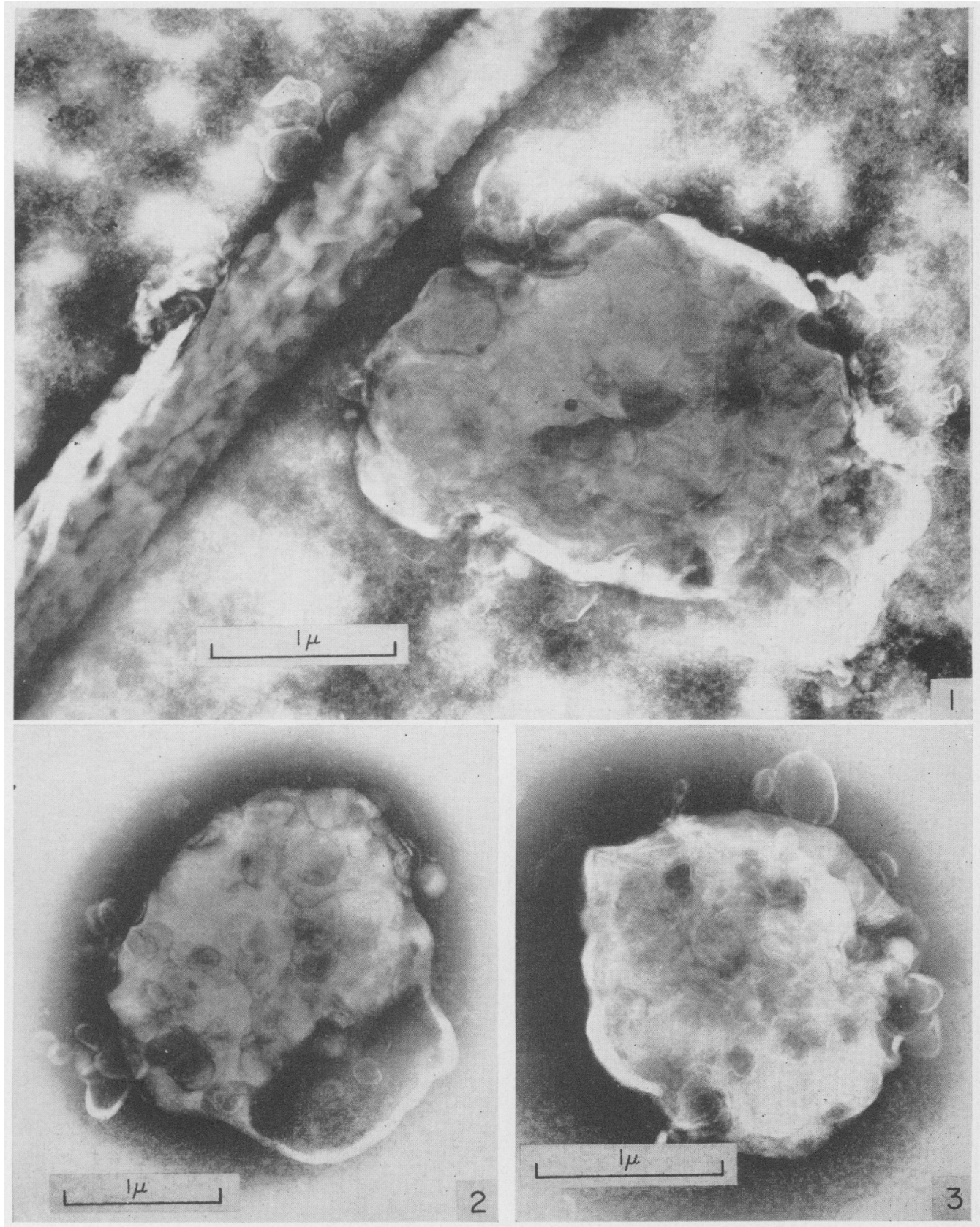

Electron micrographs of a bull spermatozoon and cytoplasmic droplets prepared at the time of counting. Preparations are unfixed and stained with $5 \%$ anmonium nolybdate. Fis. l. Free cytoplasmic droplet lying elose to ejaculated bull spermatozoon in fresh bull semen. $\times 25,500$.

Fiss. 2 and 3. Cytoplasmic droplets in the supernatant obtained when a fresh sample of bull semen was centrifuged at $300 \mathrm{~g}$ for $10 \mathrm{~min}$. $\times 21.000$ and $\times 26.300$. respectively.

(Facing f). 2fis) 
P]ATH,

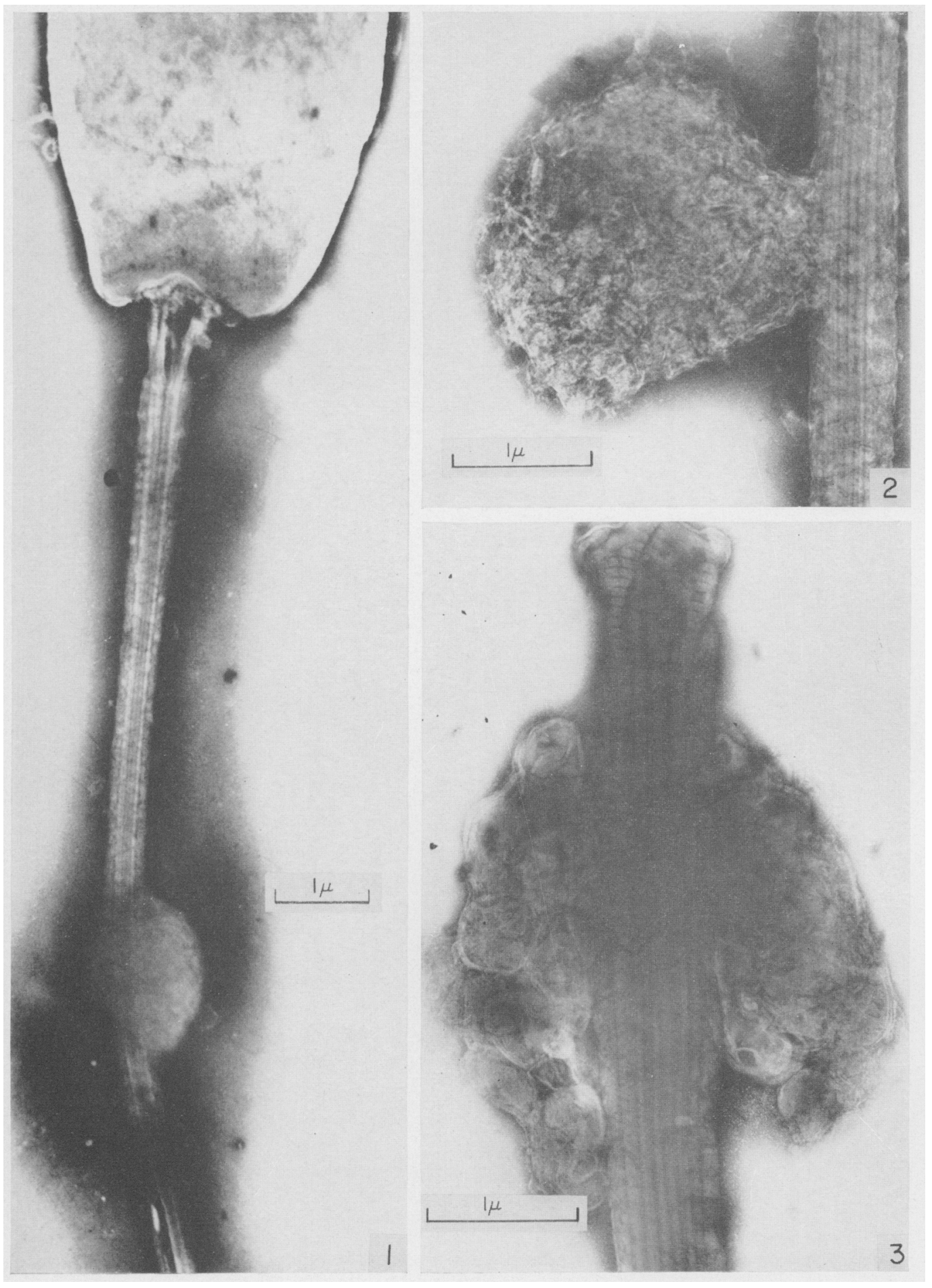

Facins (1. 269) 
distribution shown in Text-fig. 4. Three peaks were found and microscopic inspection confirmed the presence of cytoplasmic droplets and of both types of spermatozoa. The dimensions indicated for the droplet by the electronic counter agreed with those obtained by electron micrographs of droplets attached to spermatozoa (Pl. 2, Figs. 1, 2 and 3), and the difference in modal volumes of both types of spermatozoa corresponded closely with the modal volume of free droplets.

\section{Heads and tail midpieces of bull spermatozoa}

Text-figure 5 shows the distribution of volumes obtained when heads and tail midpieces of bull spermatozoa were counted separately. Visual inspection of the fractions after separation on a sucrose density-gradient showed that the tail fraction was uncontaminated but it was not possible to free the heads completely of immotile tails. This was reflected in the patterns where the tail midpieces were symmetrically distributed about a mode at $7 \mu^{3}$, while the

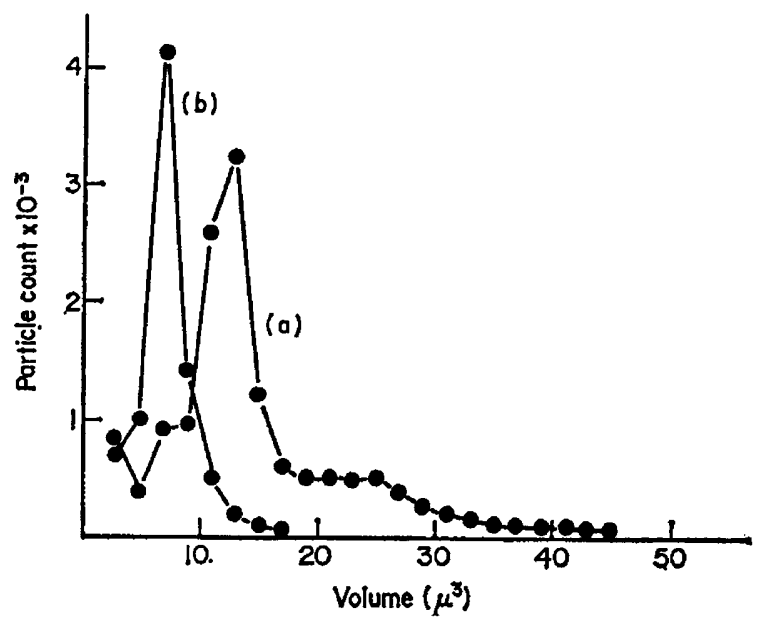

TEXT-FIG. 5. Volume distribution pattern of (a) heads, and (b) tail midpieces in semen from a Guernsey bull which produced 'naturally-decapitate' spermatozoa.

head fraction had a mode at $13 \mu^{3}$ with shoulders on either side. The shoulder to the left of the mode was attributed to contaminating tail midpieces while that to the right was due to some heads aggregated in pairs, as it occurred at a volume equal to twice the mode. The presence of aggregated pairs of heads was confirmed microscopically. It is noteworthy that the sum of the modes for the two parts of the spermatozoa agreed with the values found for the volume of intact cells.

Prepared as in Plate 1.

EXPLANATION OF PLATE 2

Fig. 1. Boar spermatozoon with cytoplasmic droplet in fresh semen. It is noteworthy that unfixed, negatively-stained preparations of boar spermatozoa showed no significant differences in structure to fixed and embedded sections (Nicander \& Bane, 1962). $\times 13,500$.

Fig. 2. Boar spermatozoon with attached cytoplasmic droplet. $\times 21,500$.

FIG. 3. Bull spermatozoon with attached cytoplasmic droplet: from the caput epididymidis. $\times 22,500$. 
Sample variation in bull semen

The mean cell volume of the spermatozoa may be calculated from the data provided by electronic counting. For twenty-nine samples of semen from five different bulls this value was calculated and found to vary as did the mode (Table 1). No significant variation between bulls was detected. When the mean cell volume was compared with the percentage of cells impermeable to eosin there was found to be some positive correlation between these properties $(r=0.75$, Text-fig. 6).

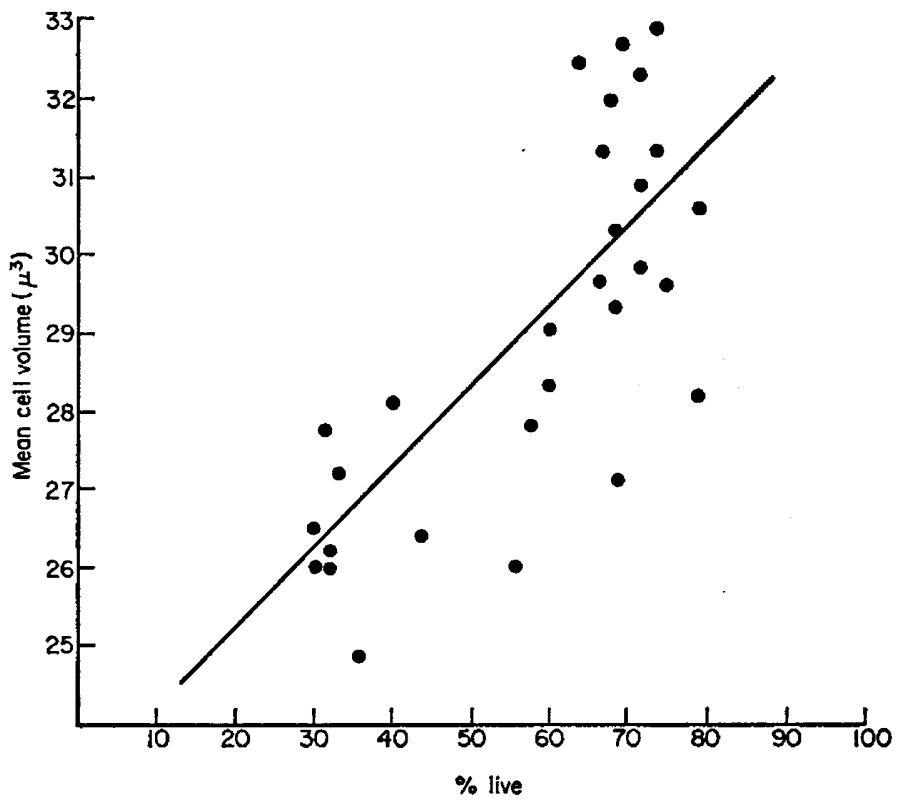

TEXT-FIG. 6. Correlation between mean cell volume of bull spermatozoa, as measured electronically, and percentage of live spermatozoa as indicated by eosin impermeability, in twenty-nine ejaculates from seven bulls. Correlation coefficient $0 \cdot 75$.

\section{DISGUSSION}

These results show that the electronic cell counting technique can yield more information about the components of mammalian semen than previously reported. Gytoplasmic droplets may be distinguished from spermatozoa in semen of bull, ram and boar and, in addition, spermatozoa bearing cytoplasmic droplets may be detected in the semen of the boar. The volumes indicated by the electronic counter for the separated heads and tail-midpieces of bull spermatozoa agreed well with the value found for the intact cells, despite the radically different shapes of the two parts of the cell. The skewness of the volume distribution of bull spermatozoa has been confirmed and shown to apply to ram and boar spermatozoa also.

The volumes found for ejaculated bull spermatozoa had modes in the range 19 to $25 \mu^{3}$ while the separated heads and tail midpieces had modes at $13 \mu^{3}$ and $7 \mu^{3}$, respectively. Iversen (1964b) reported a similar volume for bull sperm heads using the technique of surface-reflexion microscopy, but found a 
considerably lower volume for tails. While the distribution of tail midpiece volumes was symmetrical, that of heads showed some evidence of the skewness found in intact cells, although the aggregation of heads in pairs made the detection of asymmetry in volumes difficult to detect. Van Duijn (1961) has found that the heads of human spermatozoa show a similar skewness in length and breadth measured microscopically. No evidence was found for a bimodal distribution of sperm-size which might be attributed to X-and Y-chromosome dimorphism as postulated for human spermatozoa (Shettles, 1961).

Both the mean and mode of the volumes of ejaculated bull spermatozoa showed wide variation among samples but no significant variation between bulls. This variation was found to be related to the viability of the spermatozoa as indicated by the percentage of cells permeable to eosin, but the degree of correlation found was not sufficient to permit prediction of the percentage of live cells from volume measurements.

\section{ACKNOWLEDGMENTS}

The author is indebted to Dr R. A. Beatty of the Institute of Animal Genetics, Edinburgh, and to Dr H. M. Dott of the A.R.C. Unit of Reproductive Physiology and Biochemistry, Cambridge, for much valuable advice and discussion. Some samples of normal and decapitate bull semen and boar semen were kindly supplied by the latter. Surgical procedures to obtain fluid from ram testes were performed by Dr B. P. Setchell and Dr J. L. Linzell, and electron micrographs were prepared by Dr E. A. Munn. Mr M. Rennie gave much valuable technical assistance. Aid in statistical evaluation of results was provided by Mr J. G. Rowell, A.R.G. Statistics Unit, School of Agriculture, Cambridge University.

\section{REFERENCES}

Bloom, G. \& NicANDER, L. (1961) On the ultrastructure and development of the protoplasmic droplet of spermatozoa. Z. Zellforsch. mikrosk. Anat. 55, 833.

Camprell, R. C., Hancock, J. L. \& Lord Rothschied (1953) Counting live and dead bull spermatozoa. F. exp. Biol. 30, 44.

Dotт, H. M. \& Dingle, J. T. (1968) Distribution of lysosomal enzymes in the spermatozoa and cytoplasmic droplets of bull and ram. Expl Cell Res. 52, 523.

Fowler, A. K. \& HzLLmaN, A. (1965) An electronic method for counting and sizing rabbit spermatozoa. Fert. Steril. 16, 778.

Grover, F. A. (1964) The size distribution of spermatozoa in bull semen. Proc. 5th Int. Congr. Anim. Reprod., Trento, 4, 587.

Glover, F. A. \& Phipps, L. W. (1962) Preliminary study of an electronic method of counting and sizing bull spermatozoa. 7. Reprod. Fert. 4, 189.

Gordon, D. L., Moore, D. J., Thorslund, T. \& Paulsen, C. A. (1965) The determination of size and concentration of human sperm with an electronic particle counter. F. Lab. clin. Med. 65, 506.

GREGG, E. C. \& STEIDLEY, K. D. (1965) Electrical counting and sizing of mammalian cells in suspension. Biophys. F. 5, 393.

IVersen, S. (1964a) Evaluation of the number of spermatozoa in bull semen. F. agric. Sci., Camb. 62, 219.

IVERSEN, S. (1964b) Surface reflexion interference microscopy of bull spermatozoa. Q. $\mathcal{F l ~ m i c r o s c . ~ S c i . ~}$ 105, 245.

Kiniström, J. E. \& FJellström, D. (1967) Automatic counting of spermatozoa in rabbit semen. $\mathcal{F}$. Reprod. Fert. 14, 155.

Laurence, K. A. \& Carpuk, O. (1963) The counting and sizing of guinea-pig spermatozoa. Fert. Steril. 14, 451. 
Nelson, L. (1966) Enzyme distribution in 'naturally-decapitate' bull spermatozoa: acetylcholinesterase, adenylpyrophosphatase and adenosinetriphosphatase. 7. cell. comp. Physiol. 68, 113.

Nicander, L. \& Bane, A. (1962) Fine structure of boar spermatozoa. Z. Zellforsch. mikrosk. Anat. 57, 390.

Segal, S. J. \& Laurence, K. A. (1962) Automatic analysis of particulate matter in human semen. Ann. N.Y. Acad. Sci. 55, 548.

Shetrles, L. B. (1961) Differences in human spermatozoa. Fert. Steril. 12, 20.

VAn Duijn, C., JR (1961) Size frequency distribution in spermatozoa. Fert. Steril. 12, 509.

Waites, G. M. H. \& SETChell, B. P. (1964) Effect of local heating on blood flow and metabolism in the testis of the conscious ram. F. Reprod. Fert. 8, 339. 